\title{
Diagnostic Imaging in Oral and Maxillofacial Pathology
}

\author{
Hasan Ayberk Altug ${ }^{1}$ and Aydin Ozkan ${ }^{2}$ \\ ${ }^{1}$ Gulhane Military Medical Academy \\ Department of Oral and Maxillofacial Surgery \\ 2Diyarbakir Military Hospital, Dental Service
}

Turkey

\section{Introduction}

During the diagnosis of oral and maxillofacial diseases, clinical and radiological data play a major role. In this region, only a good clinical diagnosis along with a radiological examination may lead to a successful diagnosis. A successful diagnosis and evaluation of clinical examination are generally up to a profound knowledge of the normal anatomy of the region.

\section{Radiographic anatomy of oral and maxillofacial region}

X-rays (invisible rays) were discovered by W. Conrad Roentgen in 1895 . They are a form of electromagnetic radiation with high energy and are part of electromagnetic spectrum. In order to create X-ray, a target tissue is bombardized with energized electrons and then they are suddenly brought to rest. The entire process takes place in a small evacuated glass envelope which is called X-ray tube (Whaites, 2002).

\subsection{Periapical radiography}

Periapical radiography is a projection of radiographs including interoral radiographs which depict 3-4 teeth and the tissue around them (Whaites, 2002). There are two projection techniques for periapical radiography:

- $\quad$ The paralleling technique (Long-cone technique): The periapical film is stood parallel to the long axis of the teeth and the central is aimed at the right angles of the teeth and the film (Fig. 1A).

- The bisecting-angle technique: The periapical film is stood as close as possible to the palatal/lingual surface of the teeth. The film and the teeth form an angle with its apex at the point where the film is in contact with the teeth. Central ray is directed at apex of the teeth (Fig. 1B) (White \& Pharoah, 2004).

In order to create a high-quality radiograph, the central ray beam must pass through root apex or alveolar crest. Radiolucent/radioopaque images which were obtained with periapical radiography may not only depict pathological conditions which require treatment but also normal anatomic variations. Therefore, achieving a good differential diagnosis has 
an utmost importance. 10 periapical radiographs, 5 of them for the upper jaw and 5 of them for the lower jaw, are applied for kids, whereas 14 periapical radiographs, 7 of them for the upper jaw and 7 for the lower jaw, are applied for the adolescents, performed using the paralleling technique (Fig. 2). It needs to different projection angle to capture third molar. During the creation of periapical radiographs, film holders might be used in order to comply with standardization. However, free-handed positioning may also be preferred (Wood et al. 1997; Pasler, 1993).

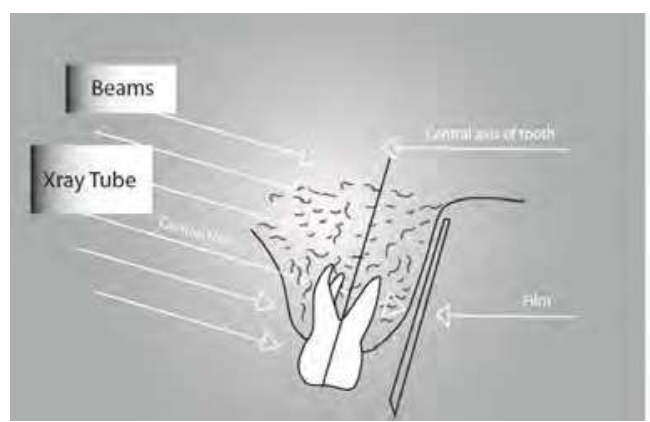

(a)

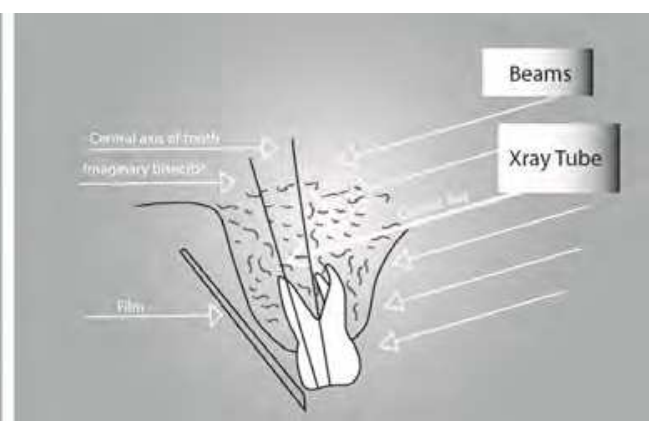

(b)

Fig. 1. (a) The paralleling technique; (b) The bisecting-angle technique.

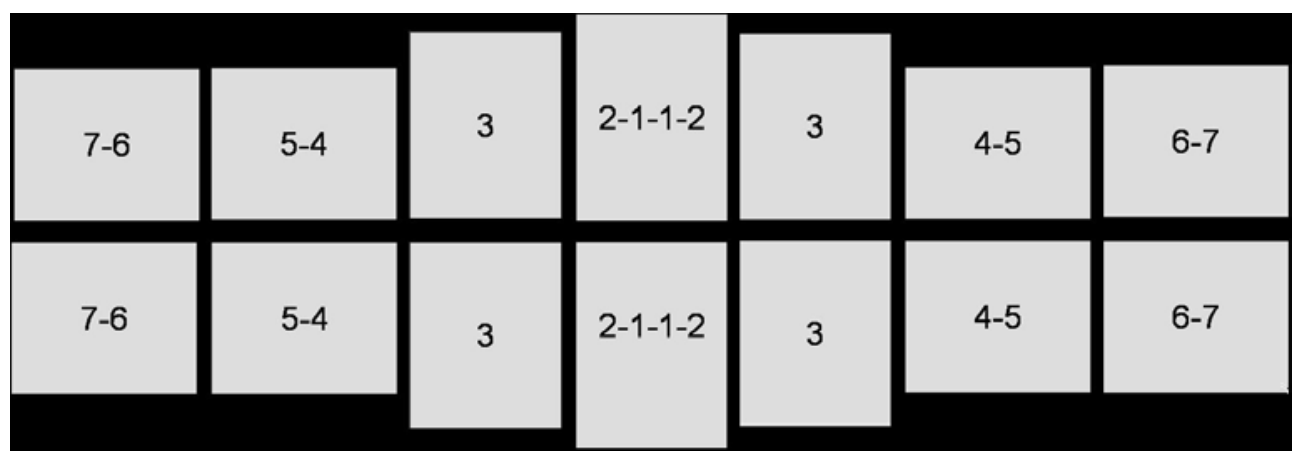

Fig. 2. Periapical radiographic survey for adolescents.

\section{Indications:}

- Evaluation of periapical and periodontal tissue health

- Before, during and/or after surgical and endodontic treatments

- Assessment of the teeth and adjacent tissue after trauma

- Evaluation of apical pathology within the alveolar bone

- To clarify of the presence/absence of unerupted teeth (Whaites, 2002). 


\subsubsection{Anatomic landmarks of periapical radiograph}

\subsubsection{Maxilla}

\section{Maxillary anterior region}

Cervical dentin of the anterior teeth is penetrated in its lateral aspects by the X-ray beam. It is seen in the radiograph as a radiolucent image which is known as "burn-out effect". The anterior portions of the nose and the median suture can also be seen clearly in the radiographs taken from maxillary anterior region (Fig.3A).

\section{Maxillary canine region}

This projection exhibits a nasal process of the maxilla and the nasal soft tissues. Nasopalatine canal, incisive foramen and anterior lobe of the maxillary sinus can also be visible in this projection (Fig.3B).

\section{Maxillary premolar region}

The radiographs which were taken from premolar region exhibit the floor of the nasal cavity and maxillary sinus, usually separated from septum above the root tip of the second premolar (Fig.3C).

\section{Maxillary molar region}

The radiographs which were taken from premolar region exhibit maxillary sinus, maxillary tuberosity, and usually the body of the zygoma. Sometimes the process of the palatal bone, the pterygoid process and coronoid process of the mandible, so-called "radix relicta" appear in the radiograph (Fig.3D) (Pasler,1993; Pasler\&Visser, 2003).

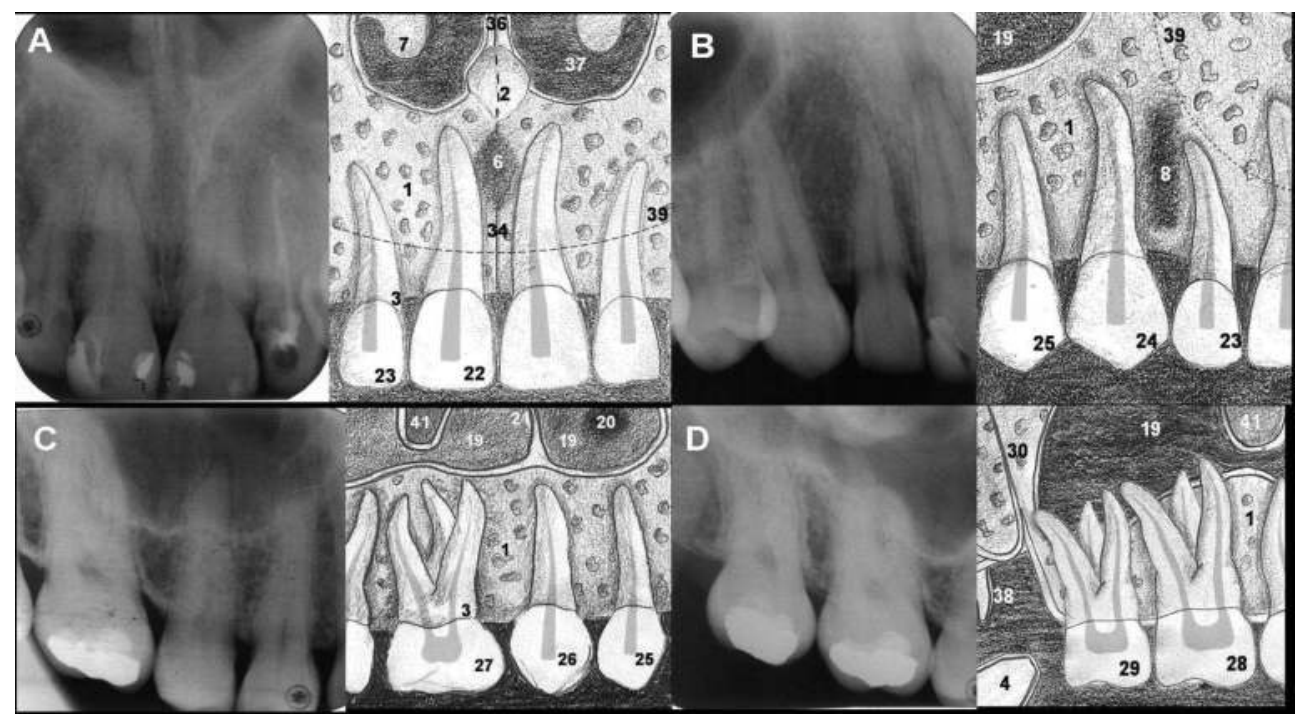

Fig. 3. A: Periapical view and schematic drawing of maxillary anterior region B: Periapical view and schematic drawing of maxillary canine region C: Periapical view and schematic drawing of maxillary premolar region D: Periapical view and schematic drawing of maxillary molar region 


\subsubsection{Mandible}

\section{Mandibular anterior region}

The radiographs which were taken from the anterior region exhibit 4 mandibular incisor teeth, mental fovea which shows a radiolucent outfit, vascular canals and the chin prominence. Burn-out effect may also be observed in this radiograph just like in the radiographs which were taken from the maxillary region (Fig. 4A).

\section{Mandibular canine region}

The radiographs which were taken from this region do not exhibit any important anatomic formation. Depending on the radiographic angle, mental foramen and enostosis surrounding it can be seen (Fig.4B).

\section{Mandibular premolar region}

The radiographs which were taken from premolar region exhibit mental foramen between the roots of the premolar, course of mandibular canal and sublingual fovea. Depending on the radiographic projection angle, mental foramen may lead to diagnostic problem. It may be seen as a periapical lesion (Fig.4C).

\section{Mandibular molar region}

The radiographs which were taken from molar region exhibit mandibular canal, mylohyoid line, external and internal oblique line (Fig.4D) (Pasler,1993; Pasler\&Visser, 2003).

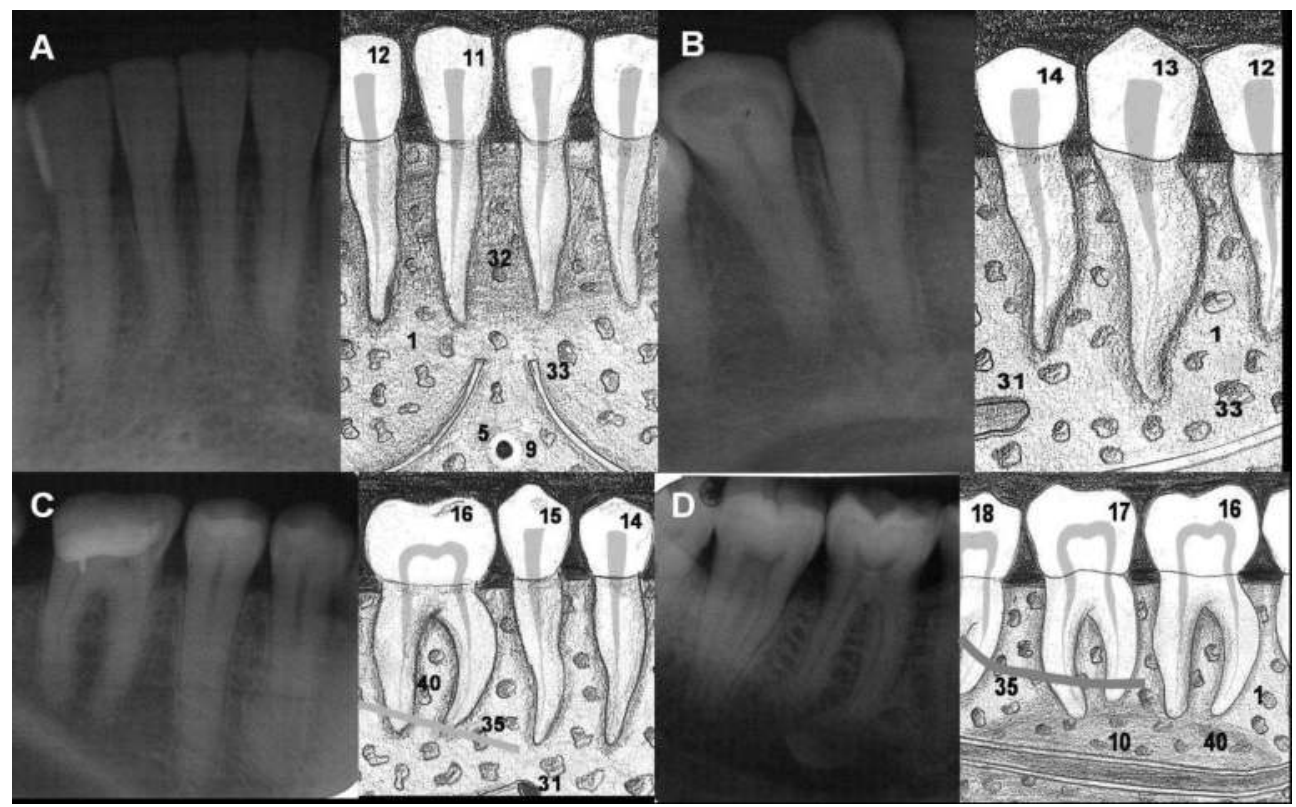

Fig. 4. A: Periapical view and schematic drawing of mandibular anterior region B: Periapical view and schematic drawing of mandibular canine region C: Periapical view and schematic drawing of mandibular premolar region D: Periapical view and schematic drawing of mandibular molar region 
Legends for Figure 3-4:

1. Alveolar bone

2. Anterior nasal spine

3. Burn-out effect

4. Coronoid process

5. Genial tubercle

6. Incisive foramen

7. Infeior nasal concha

8. Lateral fossa

9. Lingual foramen

10. Mandibular canal

11. Mandibular tooth 1 , central incisor

12. Mandibular tooth 2, lateral incisor

13. Mandibular tooth 3 , canine

14. Mandibular tooth 4, first premolar

15. Mandibular tooth 5, second premolar

16. Mandibular tooth 6, first molar

17. Mandibular tooth 7 , second molar

18. Mandibular tooth 8 , third molar

19. Maxillary sinus

20. Maxillary sinus recession

21. Maxillary sinus septum

22. Maxillary tooth 1 , central incisor

23. Maxillary tooth 2 , lateral incisor

24. Maxillary tooth 3 , canine

25. Maxillary tooth 4, first premolar

26. Maxillary tooth 5 , second premolar

27. Maxillary tooth 6 , first molar

28. Maxillary tooth 7 , second molar

29. Maxillary tooth 8 , third molar

30. Maxillary tuberosity

31. Mental foramen

32. Mental fossa

33. Mental ridge

34. Middle suture of hard palate

35. Mylohyoid ridge

36. Nasal septum

37. Nasal cavity

38. Processus hamularis

39. Soft tissue of nose

40. Submandibular fossa

41. Zygomatic arch

\subsection{Panoramic radiography}

Panoramic radiography, also known as an orthopantomogram, is a panoramic scanning dental X-ray of the two-dimensional view of the jaws and their supporting structures from ear to ear. It is obtained with patient, whose head stands between X-ray generator and the 
film. The main advantage of panoramic radiography is the fact that it is clinically useful for diagnostic problems associated with maxilla and mandible. One of the disadvantages of it is that the images do not exhibit a fine anatomically detailed outfit gained from periapical radiographs. Another problem related to orthopantomogram includes unequal magnification (Lurie, 2004).

Indications of panoramic radiographies are included in the following cases:

- Detection of the presence/absence of unerupted teeth

- Evaluation of relationship of the upper posterior teeth with maxillary sinus

- Evaluation of relationship of the lower posterior teeth with canalis alveolaris inferior

- Suspicion of asymptomatic swellings

- Radiographic examination of temporomandibular joint disturbances

- Examination of odontogenic, nonodontogenic cysts and tumors

- Evaluation of alveolar crest for insertion dental implants

- Evaluation of maxillomandibular region following trauma

- Examination of maxillary/mandibular surgical interventions

\subsubsection{Anatomic landmarks of panoramic radiograph}

While evaluating panoramic radiographs, first of all, normal anatomic structure of the region must be known well. Complicated structure of the regions, superposition of these structures and variations of the projection orientations may lead to problems during the evaluation process.

There are four diagnostic regions in the panoramic radiography:

- Dentoalveolar Region

- Maxillary Region

- Mandibular Region

- Temporomandibular, Retromaxillary and Cervical Region.

\section{Dentoalveolar region}

It is surrounded by maxillary sinus and inferior border of the nasal cavity from above and mandibular canal from below. Frontal side of ramus takes place on its left and its right. The teeth which are located in the upper and lower jaws and alveolus supporting them are seen in this region. Caries, fillings and prostheses are evaluated for the teeth whereas periodontal problems and intraalveolar pathologies related to the teeth are evaluated for alveolus (Fig.5).

\section{Maxillary region}

It is surrounded by orbita from above and maxillary sinus and the inferior border of the nasal cavity from below. Coronoid processus of the mandible and zygoma take place on its left and its right. Maxillary sinuses, zygomatic complex, nasal cavity and conchae, sphenoid, ethmoid, palate, frontal bones and pterygomaxillary fissure can be observed in this region. Lefort fractures and maxillary sinus pathologies are evaluated in this region (Fig.5). 


\section{Mandibular region}

It is comprised of the mandibular teeth and mandibula rather than alveolus. Condylar and coronoid processes, ramus, body and angle and symphysis take place in this region. Mandibular canal, mental foramen, submandibular fossa, superimposed shadow of cervical vertebrae, external oblique ridge, posterior surface of tongue, soft palate and uvula, floor of nasopharynx and hyoid bone can also be observed in this region. Internal bone lesions and fractures are evaluated (Fig.5).

\section{Temporomandibular, retromaxillary and cervical region}

It is surrounded by temporal bone from above, and hyoid bone from below. Anterior of the ramus of the mandible takes place in its anterior. Cervical vertebra takes place in its posterior. The most important anatomic formation in this region is temporomandibular joint (TMJ). TMJ is comprised of glenoid fossa, articular eminence and articular process of mandibular condyle. Cervial vertebra, ear lobe, soft palate and uvula, posterior pharyngeal airway, floow of nasopharynx, zygomatic arch, styloid process of temporal bone, pterygomaxillary fissure and maxillary tuberosity can be observed in this region. Fractures in this region are evaluated (Fig.5) (Lurie, 2004).

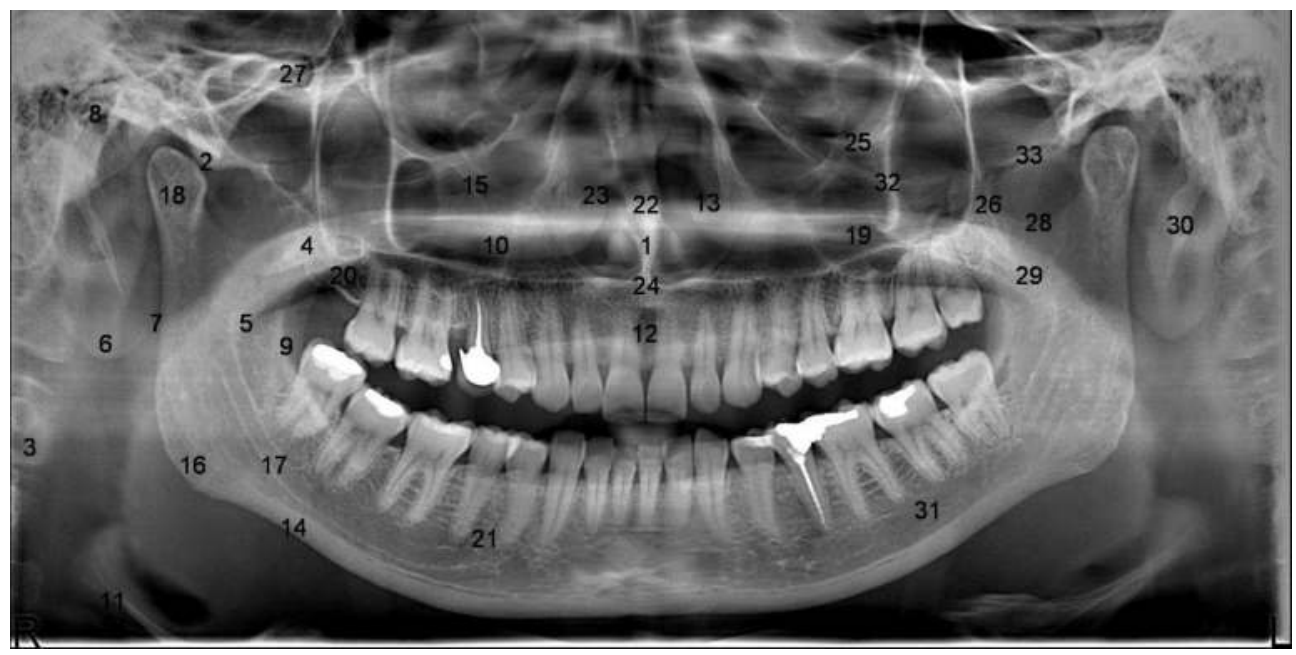

Fig. 5. Panoramic radiograph with marked anatomic structures

Legends for Figure 5:

1. Anterior nasal spine

2. Articular tubercle of the temporal bone

3. Cervical vertebra

4. Coronoid process

5. Dorsum of tongue (Shadow)

6. Ear lobe

7. Epipharynx 
8. External auditory canal

9. External oblique ridge

10. Hard palate

11. Hyoid bone

12. Incisive foramen

13. Inferior nasal concha

14. Inferior border of mandible

15. Infraorbital canal

16. Mandibular angle

17. Mandibular canal

18. Mandibular condyle

19. Maxillary sinus

20. Maxillary tuberosity

21. Mental foramen

22. Nasal septum

23. Nasal cavity

24. Nasopalatine canal

25. Orbital rim

26. Pterygoid process of sphenoid bone

27. Pterygopalatine fossa

28. Sigmoid notch

29. Soft palate

30. Styloid process

31. Submandibular fossa

32. Zygoma

33. Zygomatic arch

\subsection{Dental computed tomography}

Computed tomography was discovered by Hounsfield in 1974. After improvements, nowadays, dental computed tomography is performed for diagnosis of oral and maxillofacial pathology in most patients. Its advantage over 2D radiography is the fact that it can eliminate the superimposition of images of adjacent tissues. Since it provides bone images at the highest quality, it is the most widely used imaging technique (Curtain et al., 1998; Karjodkar,2006). Tomographic images are taken as trans-axial cross sections. These images are stored on the computer and then recreated from the cross sections passing through the surfaces which are desired to be observed. This is called multiplanar reformation. This way, axial, sagittal and coronal planes of the material that was imaged can be obtained. When these planes are combined by means of a software application, a 3D image may also be obtained. The images are obtained with the patient supine and during quite respiration. Contrast agent injection may be needed to evaluate soft tissues. When taking a computed tomography of oral and maxillofacial region, images are acquired from the top of the frontal sinus to the sub mental region (Hermans et al., 2006). Computerized tomography is used in maxillofacial surgery, reconstructive surgery, orthognatic surgery, dental implant applications, and detection of lesions like cyst/tumor, trauma and temporomandibular joint diseases. 
Dental computed tomography has a number of advantages over other conventional radiography:

- Undesired superimposition of other tissues in the region is eliminated.

- Thanks to the high-resolution of computerized tomography, differences between the tissues with different physical densities can be distinguished better.

- It is possible to obtain images of the tissues which are located on axial, coronal sagittal planes.

- It is especially a very useful tool for the planning of dental implant insertion.

- It has no magnification and no distortion.

- In the presence of formations like cysts/tumors, it can be determined whether this formation has a solid or a liquid structure by means of density measurements (Frederiksen, 2004).

Dental computed tomography has also disadvantages over other conventional radiography:

- Administration of contrast agent is necessary for imaging soft tissue

- More radiation exposure

- Degradation of image quality by metallic objects, like as dental crown, fillings

\subsubsection{Anatomic landmarks of dental tomography}

This chapter presents the imaging of normal anatomic structures by dental tomography on axial, coronal, sagittal planes and in 3D view (Fig.6,7,8).

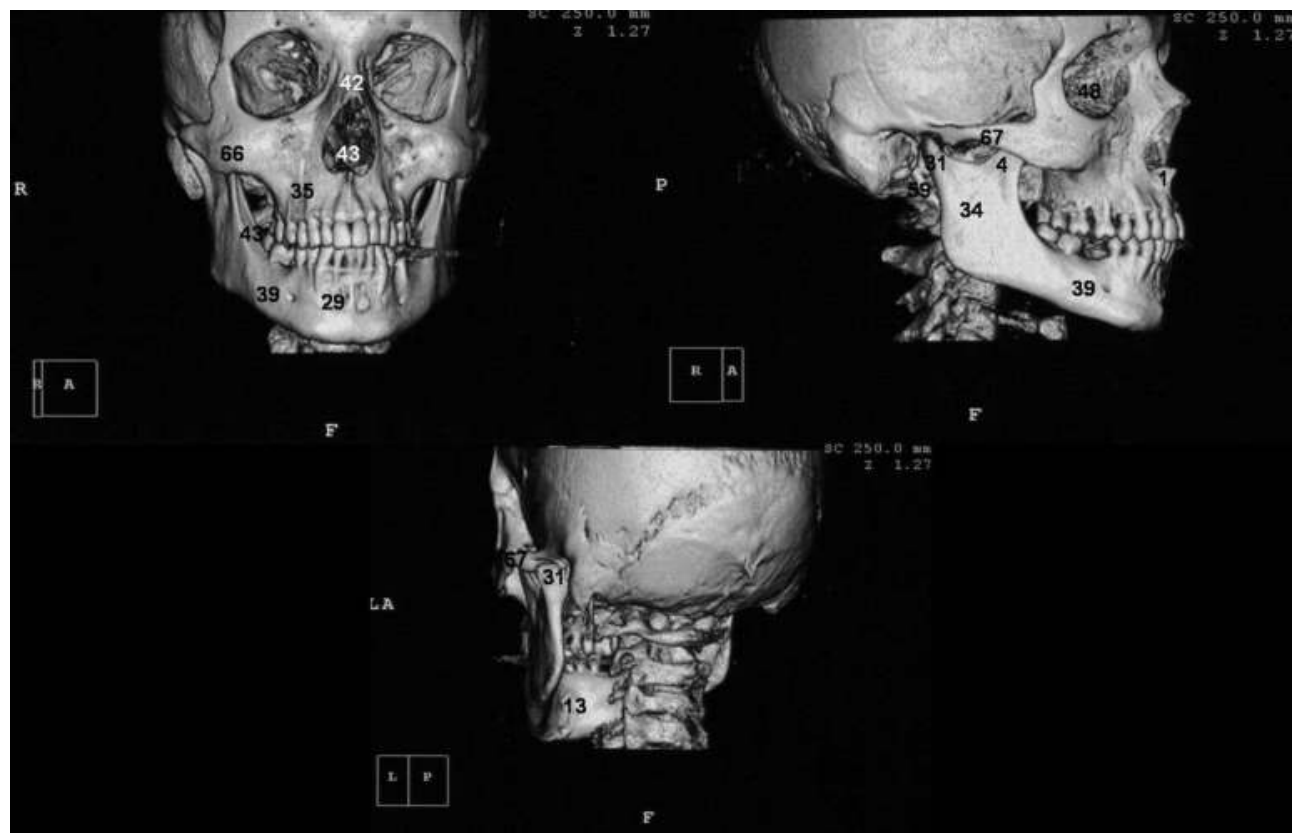

Fig. 6. 3D CT anatomy of the facial skeleton 

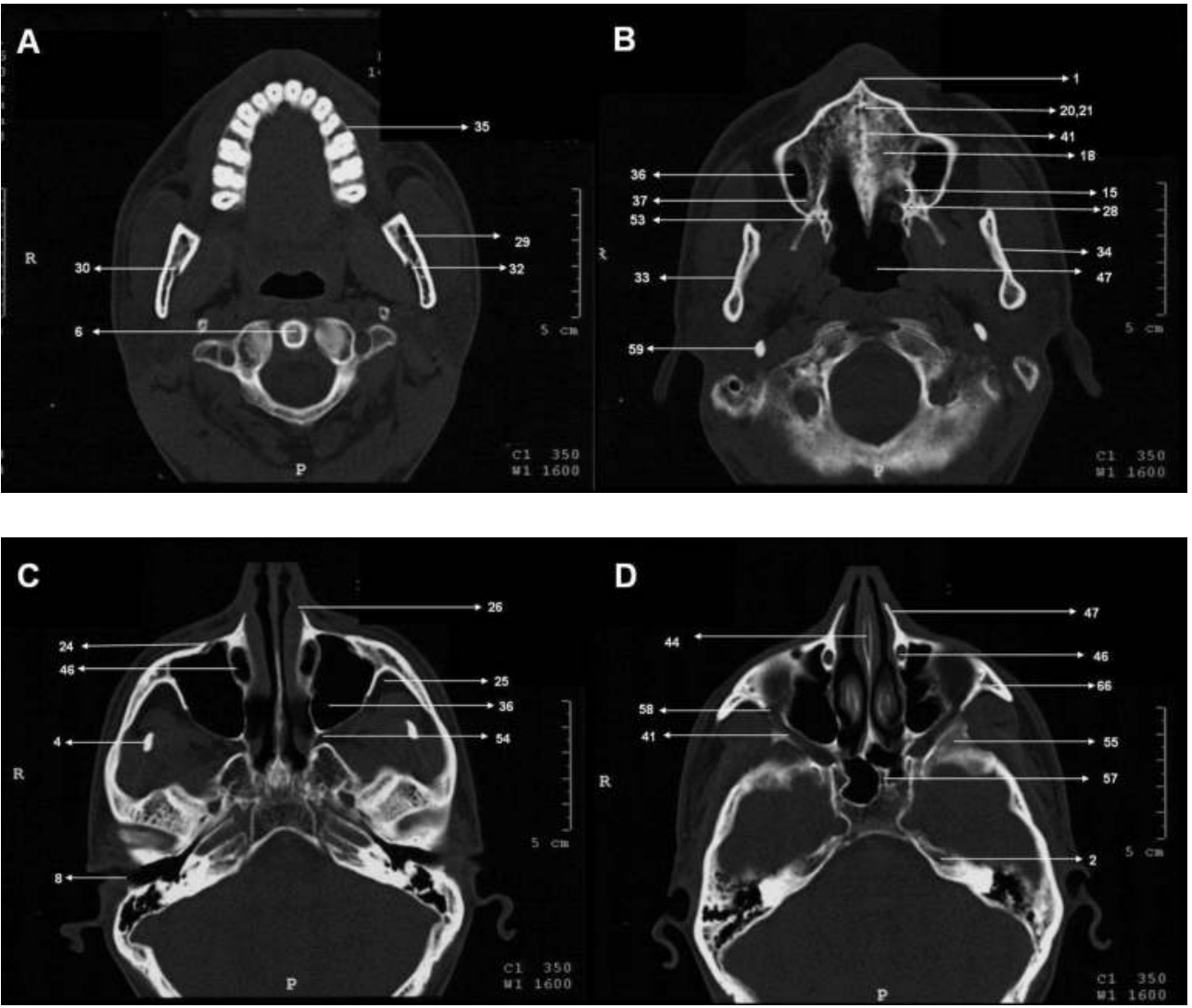

Fig. 7. (A,B). Axial CT anatomy of the facial skeleton; (C,D). Axial CT anatomy of the facial skeleton

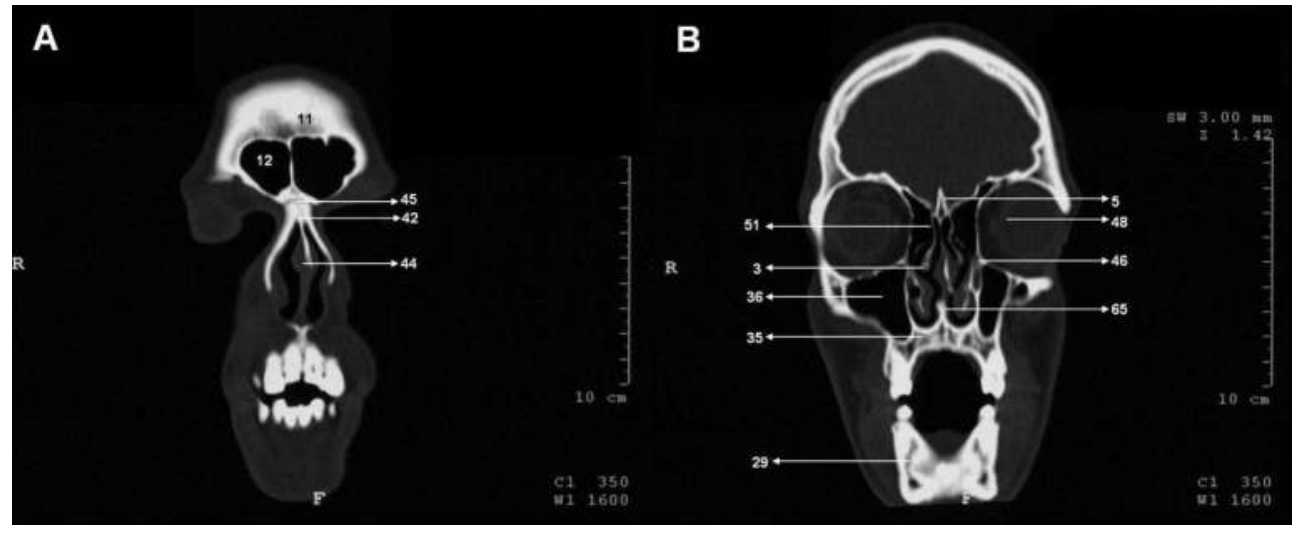



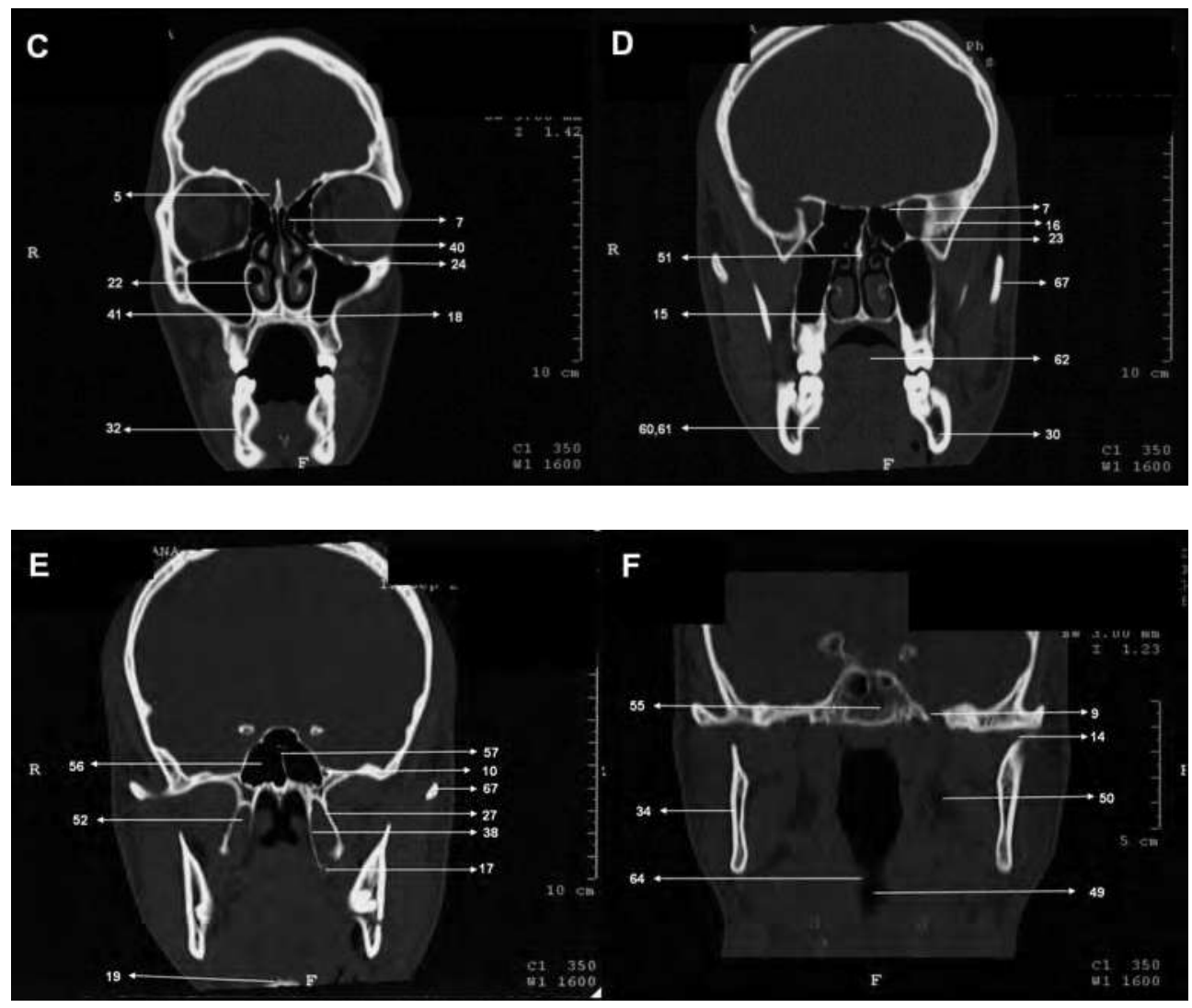

Fig. 8. (A,B). Coronal CT anatomy of the facial skeleton; $(\mathrm{C}, \mathrm{D})$. Coronal CT anatomy of the facial skeleton; (E,F). Coronal CT anatomy of the facial skeleton

Figure legends for figure 6,7,8:

1. Anterior nasal spine

2. Carotid canal

3. Concha bullosa

4. Coronoid process

5. Crista galli

6. Dens axis

7. Ethmoid sinus

8. External auditory canal

9. Foramen ovale

10. Foramen rotundum

11. Frontal bone

12. Frontal sinus

13. Genial tubercle of mandible

14. Glenoid fossa

15. Greater palatine canal 
16. Greater wing of sphenoid bone

17. Hamulus of medial pterygoid plate

18. Hard plate

19. Hyoid bone

20. Incisive canal

21. Incisive foramen

22. Inferior meatus

23. Inferior orbital fissure

24. Infraorbital canal

25. Infratemporal fossa

26. Lacrimal bone

27. Lateral pterygoid plate

28. Lesser palatin canal

29. Mandible

30. Mandibular canal

31. Mandibular condyle

32. Mandibular foramen

33. Mandibular notch

34. Mandibular ramus

35. Maxilla

36. Maxillary sinus

37. Maxillary tuberosity

38. Medial pterygoid plate

39. Mental foramen

40. Middle meatus

41. Middle suture of hard palate

42. Nasal bone

43. Nasal cavity airway

44. Nasal septum

45. Nasofrontal suture

46. Nasolacrimal canal

47. Nasopharynx

48. Orbit

49. Oropharynx

50. Parapharyngeal space

51. Perpendicular plate of ethmoid bone

52. Pterygoid fossa

53. Pterygoid process of sphenoid bone

54. Pterygopalatine fossa

55. Sphenoid bone

56. Sphenoid sinus

57. Sphenoid sinus septum

58. Sphenozygomatic suture

59. Styloid process

60. Submandibular space

61. Submandibular gland

62. Tongue

63. Trigomun retromolare

64. Uvula 
65. Vomer

66. Zygoma

67. Zygomatic arch

\section{Radiographic description of oral and maxillofacial pathology}

\subsection{Radiolucent/radiopaque lesions of the jaws}

Odontogenic cysts and tumors present problems of diagnosis, radiology and histopathology. In general, their differential diagnosis requires radiographic clinical data, since many of them possess similar histological characteristics. Radiologic appearance of jaw cysts and odontogenic tumors varies considerably. The common lack of physical findings and the development of most of these lesions within the confines of the bone make radiologic investigation and interpretation uniquely important. Radiographs are also important in treatment planning for surgical removal. They can evaluate encroachment on vital structures, extent into soft tissue, size of the lesion, and requirements for reconstruction. Radiography allows for creation of a radiologic differential diagnosis. (Escobar et al.,2007)

\subsubsection{Radiolucent lesions of the jaws}

- Dental granuloma

- Radicular cyst

- Dentigerous cyst

- Keratocystic odontogenic tumor

- Ameloblastoma

- Incisive canal cyst

- Simple bone cyst

- Central giant cell granuloma

- Odontogenic myxoma

\subsubsection{Radiopaque lesions of the jaws}

- Odontoma

- Torus

- Osteoma

- Osteochondroma

- Cementoblastoma

- Fibrous dysplasia (late stage)

\subsubsection{Mixed radiolucent/radiopaque lesions of the jaws}

- Fibrous dysplasia (early stage)

- Ossifying fibroma

- Cemento-osseous dysplasia

- Chronic osteomyelitis

- Osteosarcoma

- Metastasis 


\section{Dentigerous cyst}

Dentigerous cysts are the second most common odontogenic cysts after radicular cysts. It surrounds the crown of an impacted tooth, caused by fluid accumulation between the reduced enamel epithelium and the enamel surface, resulting in a cyst in which the crown is located within the lumen and roots outside. It is usually asymptomatic but produces some swelling or pain when become large or inflamed. It is associated clinically with impacted tooth most commonly an unerupted $3^{\text {rd }}$ molar (mandibular- more than maxillary), then maxillary canines, rarely involve deciduous teeth. Radiographically, the dentigerous cyst appears as a unilocular radiolucency of variable size with well-defined sclerotic borders, associated with the crown of an unerupted tooth. In an infected cyst the borders may be ill-defined. The radiographic appearance of such a cyst, though quite typical, is not diagnostic (Daley\&Wysocki, 1995). The treatment of dentigerous cysts is determined by the size of the lesion. Small lesions should be removed by surgery; larger cysts are treated by marsupialization or decompression. The possible complications of the dentigerous cysts are the permanent bony deformation from its expansive destruction of bone, loss of essential permanent dentition or its innervation of the mandibular nerve. Dentigerous cysts with long evolution can present areas with keratin or dysplasic changes of its epithelial revetment with development of an ameloblastoma or an epidermoid carcinoma (Fig.9) (Weber, 1993).

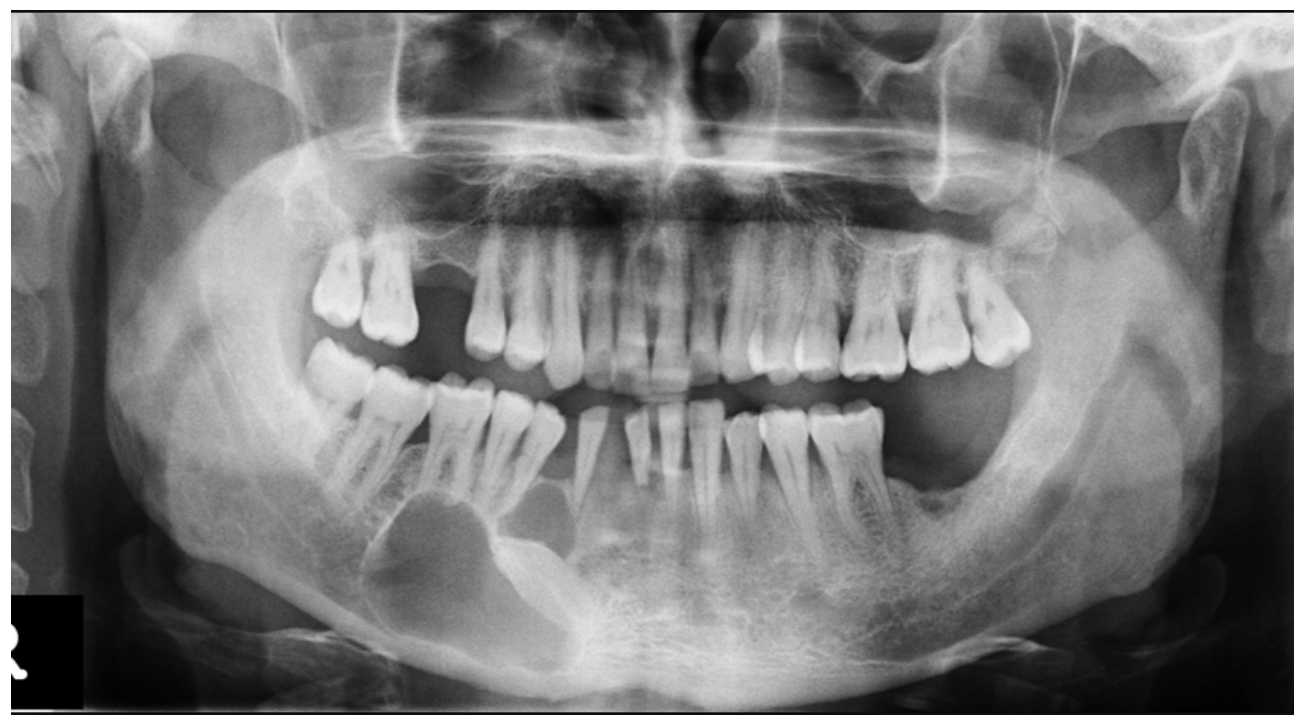

Fig. 9. Panoramic radiograph shows a well-defined expansile radiolucent lesion in the right mandible and unerupted right canine.

\section{Radicular cyst}

Radicular cysts are the most common cyst of the jaws. They are most frequent between the ages of 20 and 60 years. Radicular cysts may cause slowly progressive painless swellings, with no symptoms until they become expansion of the cortical plates. If the infection enters, the tooth and swelling develop all the painful symptoms of an abscess. Initially, the swelling 
is rounded and hard. Later they are caused the demolition of cortical plate, than the swelling is rubbery and fluctuant because of the cyst fluid. Large cysts may involve a complete quadrant with some of the teeth occasionally mobile and some additional pulps nonvital. Radiographically, radicular cyst appears well defined radiolucent area. Infection of a cyst causes resorption of the surrounding tissue. If the cyst extends slowly, a condensed radiopaque periphery is present. Enucleation is usual method for the treatment of radicular cyst. Larger cysts are treated by marsupialization (Fig.10) (Cawson\&Odell, 2002; Wood et al.,1997; Sahin et al., 2009).

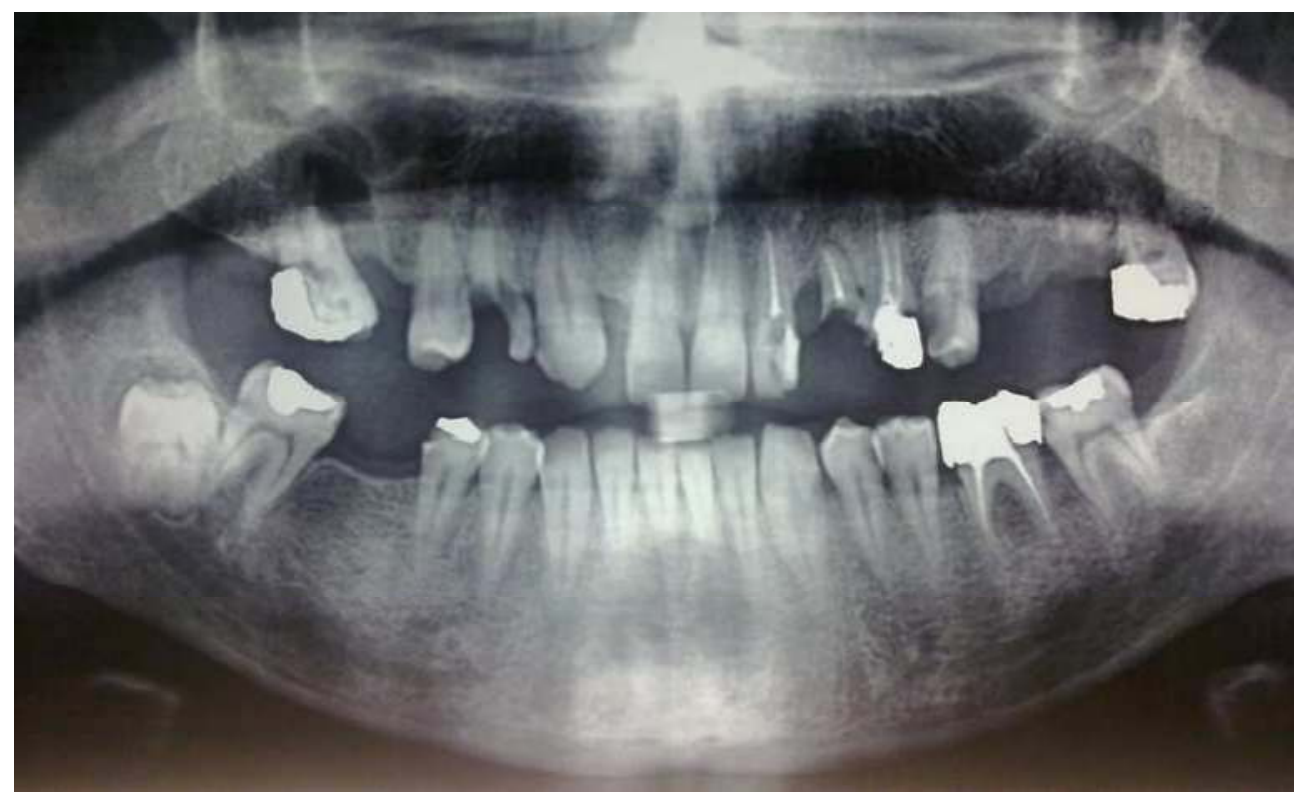

Fig. 10. Radiographic appearance of the radicular cyst (maxillary right second molar region) on the panoramic radiograph

\section{Keratocystic odontogenic tumor}

The most recent classification of the World Health Organization (WHO) reallocated keratocyst (keratinized primordial cyst) within the classification of odontogenic tumours under the term "keratocystic odontogenic tumor." It has specific histopathological features and clinical behavior, it makes up to $10-20 \%$ of all developmental odontogenic cyst (Barnes et al.,2005). Keratocystic odontogenic tumor occurs more in mandible $80 \%$ (posterior body and ascending ramus). It grows in anterior-posterior direction within medullary cavity of the bone without causing obvious bone expansion. This is useful to differentiate clinical and radiographic dentigerous and radicular cyst of similar size which produce bone expansion. Multiple keratocystic odontogenic tumor is seen in nevoid basal cell carcinoma (gorlin syndrome). Radiographically, it is well defined radiolucent area with smooth corticated margin. Large lesions in posterior body and ascending ramus of the mandible appear as multilocular radiolucency. An unerupted tooth is involved in the lesion in $25-40 \%$ of cases. The treatment of keratocystic odontogenic tumor is complete 
removed by enucleation and curettage it has tendency to recurred because of friable nature of cyst wall that result in fragment or due to formation of new cysts from dental lamina (daughter cysts). Marsupialization has been effective in reducing the size of the cyst (Fig.11) (Mendes RA et al., 2010)

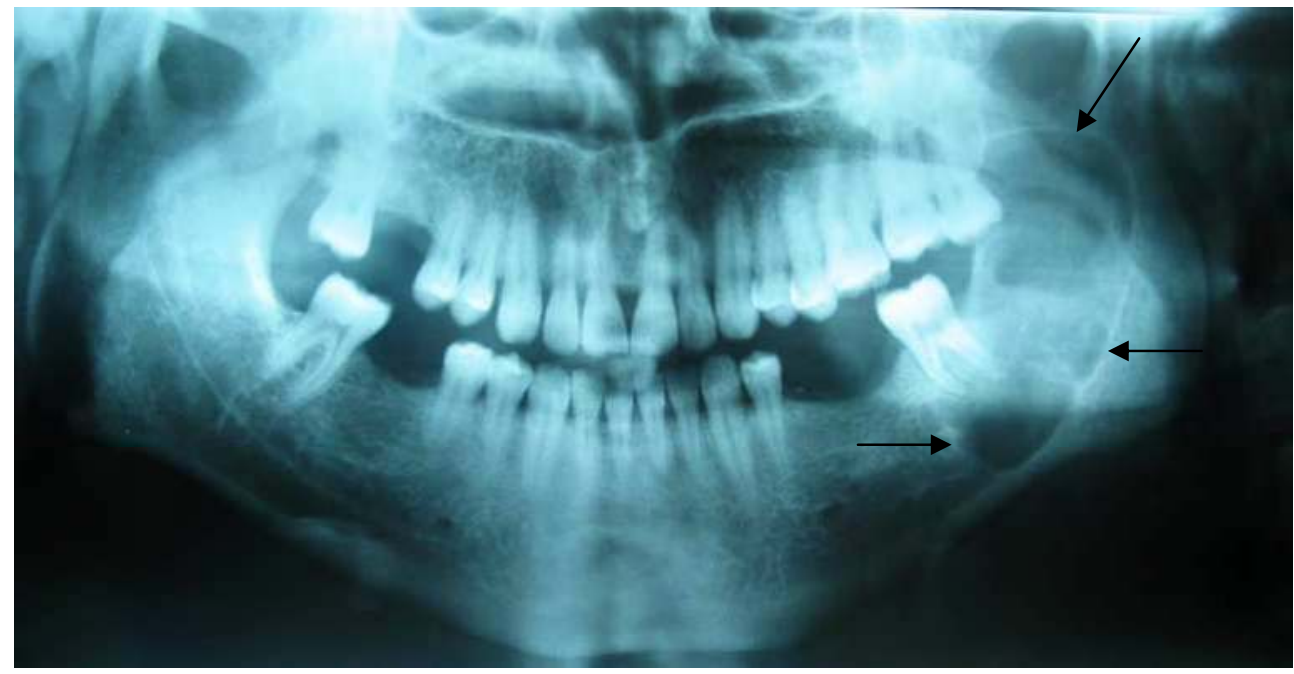

Fig. 11. Panoramic radiograph shows an ellipsoid, expansile, well-corticated, radiolucent lesion in left mandibular body and ascending ramus.

\section{Lateral periodontal cyst}

Lateral periodontal cyst is rare asymptomatic lesion, mainly in mandible in canine-premolar region. It is usually seen by chance in routine radiographs. Radiographically, it appears as a well circumscribed radiolucent area located laterally to the roots of vital tooth. Occasionally this cyst appears as multilocular (poly cystic) named botryoid odontogenic cyst. The radiographical picture is not diagnostic. Lateral periodontal cyst should be enucleated. If the affected tooth is healthy, it can be retained (Fig.11) (Cawson\&Odell, 2002).

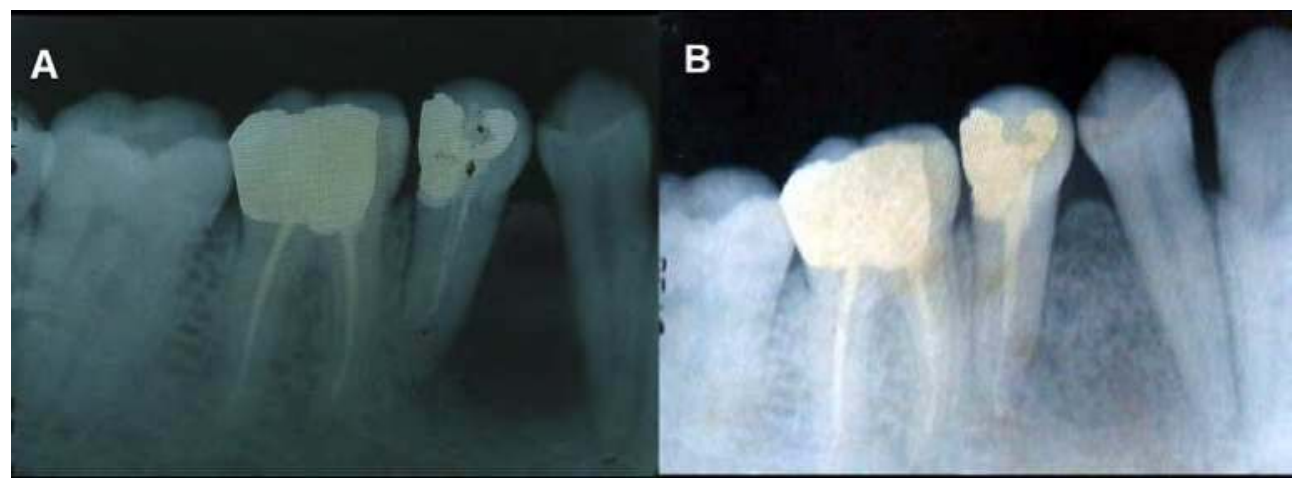

Fig. 12. Periapical view of lateral periodontal cyst A. Pre-treatment B. Post-treatment 


\section{Ameloblastoma}

Ameloblastoma are most common tumors of jaws. The majority of ameloblastoma are benign, with less than $1 \%$ showing malignant behavior. The most common site of ameloblastoma is the ascending ramus and proximal body of the mandible $(80 \%)$. Based on radiological appearance, ameloblastomas are divided into two subtypes. Multicystic ameloblastomas account for approximately $85 \%$ of all ameloblastomas and occur in the third to seventh decades of life. On radiographs, it is typically form rounded, cyst-like, radiolucent area appear multilocular. There is marked buccolingual cortical expansion with internal osseous septae, giving rise to a "soap bubble" appearance. Tooth displacement or root resorption may occur. Unicystic ameloblastomas occur in a younger age group and tend to be non-invasive. They present as a well-circumscribed, unicystic, radiolucent lesion, mostly in the region of the mandibular third molar (DelBalso, 1998). Treatment is by wide excision, preferably taking up to $2 \mathrm{~cm}$ of apparently surrounding normal tissue. Unicystic ameloblastomas can be enucleated with low risk of recurrence (Cawson\&Odell, 2002).

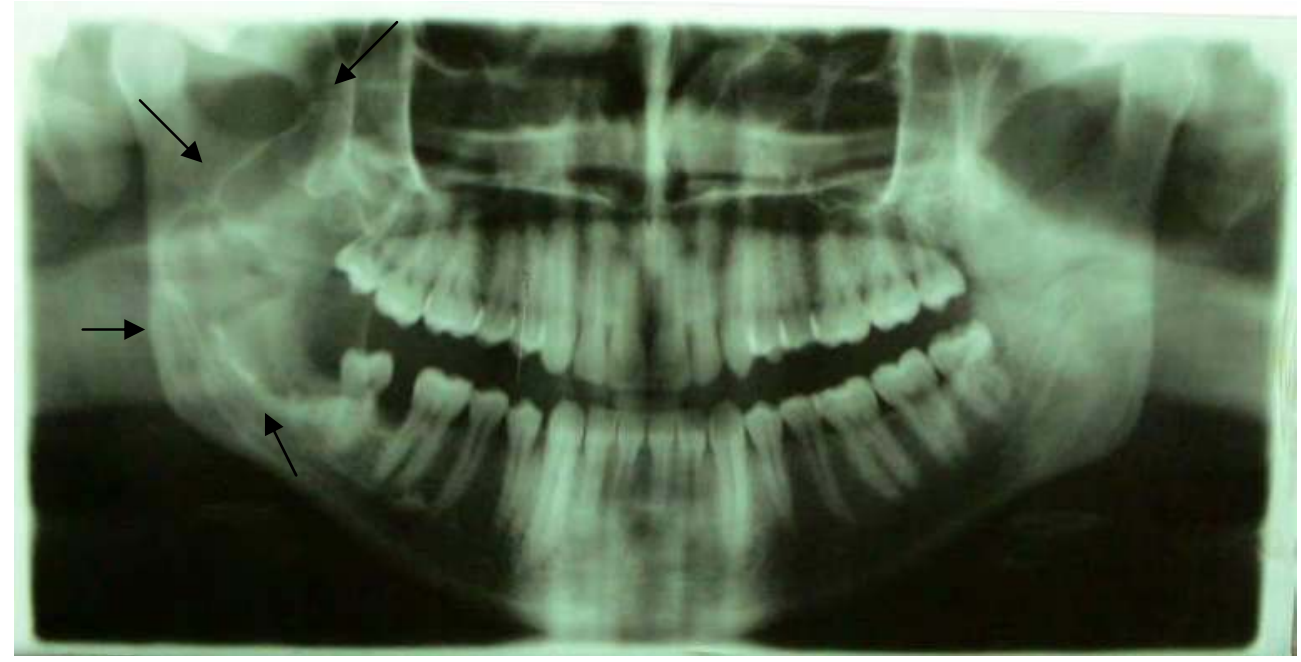

Fig. 13. Panoramic radiographic view of ameloblastoma of mandibular ramus.

\section{Central giant cell granuloma}

Central giant cell granulomas (CGCG) typically occur in patients younger than 30 years of age, more often in females. The lesion is more common in the anterior part of mandible with a tendency to cross the midline. In the early stage, the lesion manifests as a small unilocular lucent lesion. However, with development, it appears multilocular with fine trabeculae. They may cause a variable degree of bony expansion, divergence of roots and root resorption. Brown tumour of hyperparathyroidism can mimic CGCGs radiologically as well as pathologically; however, the patient's age, radiological changes in other bones, and biochemical findings help in differentiation (Altug et al., 2011b). 


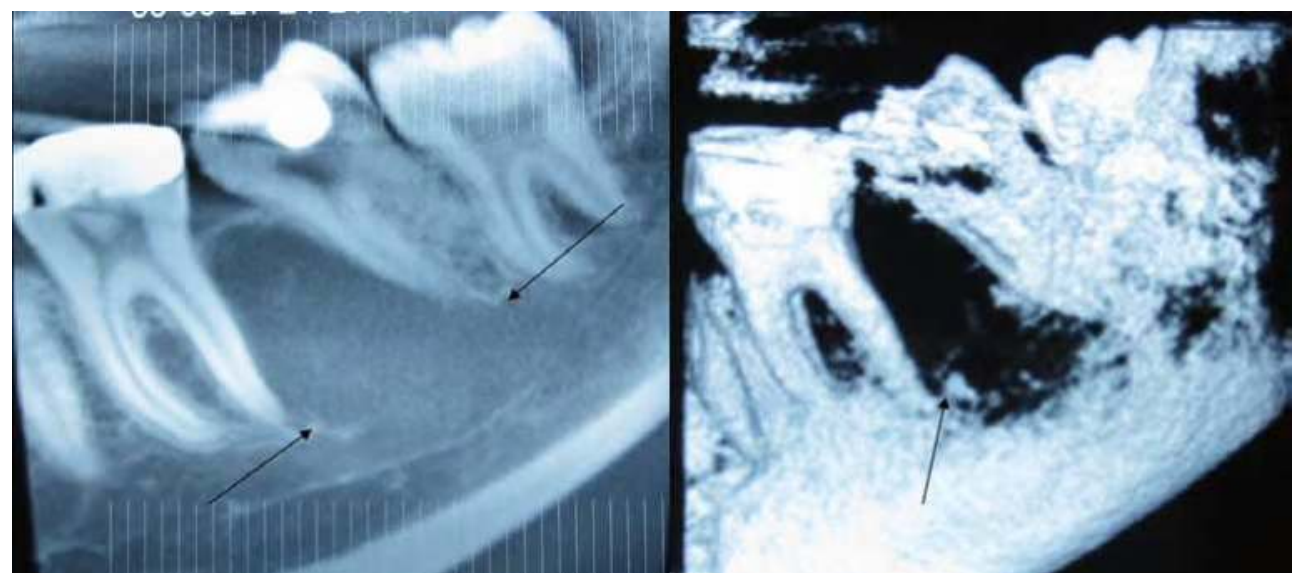

Fig. 14. Panoramic radiographic view of CGCG of mandibula.

\section{Odontoma}

Odontomas are considered to be a hamartomatous lesion rather than a neoplasm. Most cases are diagnosed in the second decade of life, and are usually associated with an impacted tooth. Radiologically, it is seen as a radiopaque mass surrounded by thin radiolucent space. The compound odontomas are composed of multiple well-formed teeth whereas the complex odontomas appear as an irregular calcified tissue. A related but very rare lesion is ameloblastic fibro-odontoma. Most cases occur in young males involving posterior jaws and may expand into the ramus. The amount of radiolucent internal structure exceeds the odontomas component (Weber et al., 1993; Altug et al, 2010b).

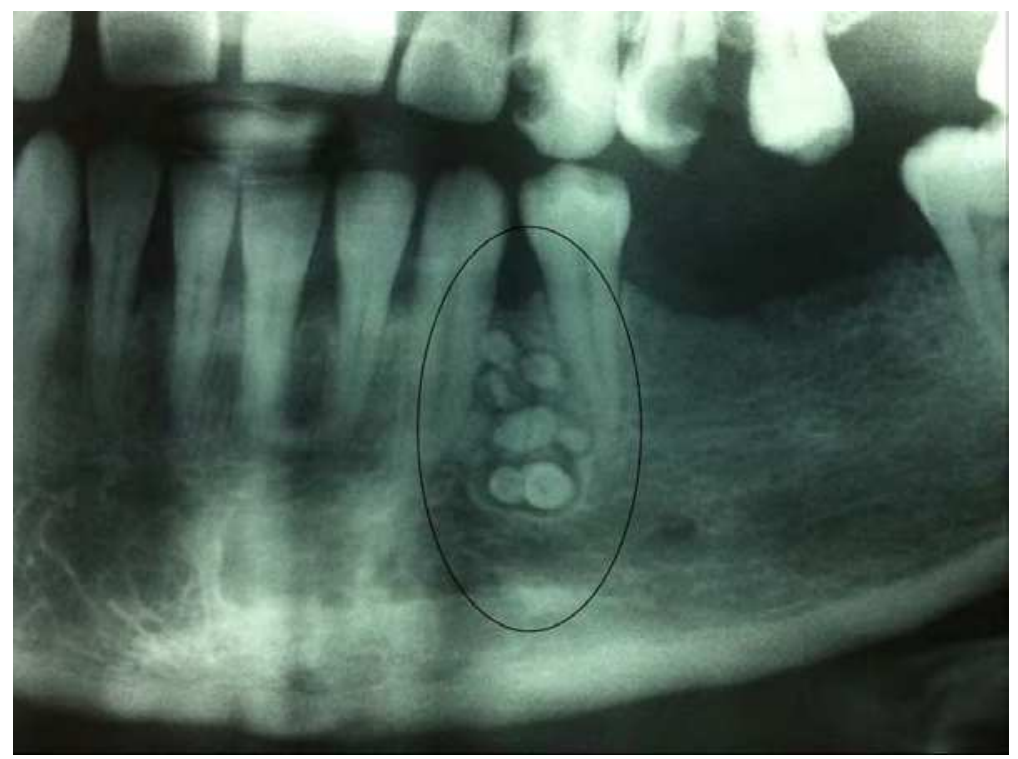

Fig. 15. Panoramic radiographic view of odontoma of mandibular canine region. 


\section{Ossifying fibroma}

Ossifying fibroma is rare. It is slow expansile growth and it can expand the cortices and displace adjacent structures. True benign tumors of mesenchyme are with strong predilection for toothbearing sections of jaw. Patients are usually females in 20-40s. Radiographically, early lesion is radiolucent with varying degrees of calcification and has well circumscribed margins. If the lesion is more opaque shows that the lesion is mature. The patterns of calcifications have no effect on the lesions behavior. Small lesions should be removed by enucleation and curettage. However, large lesions ( $5 \mathrm{~mm}$ margin) which have distorted the jaw require local resection. Recurrence is rare (Fig. 16) (Cawson \& Odell, 2002; Ortakoğlu et al., 2006).

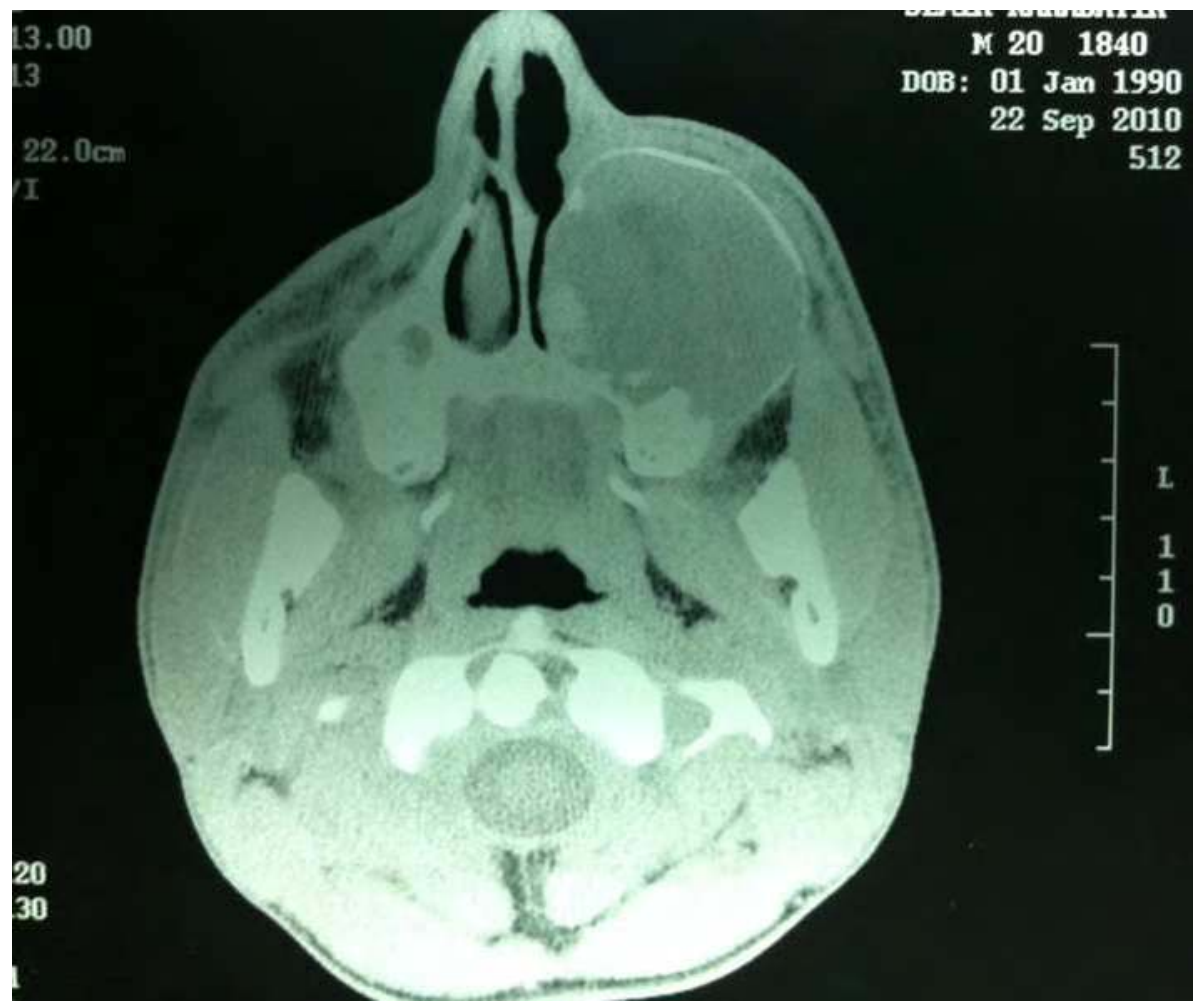

Fig. 16. Axial CT view of maxillary ossifying fibroma

\section{Cementoblastoma}

Cementoblastoma is a benign neoplasm and forms a mass of cementum and cementum-like tissue on roots of teeth. It is usually affect of posterior region of mandible, especially mandibular first molar. Clinically, cementoblastoma mainly affects young adults, particularly males. It is slow-growing and usually asymptomatic; but pain and swelling have been reported in a number of cases. Radiographically, there is typically a radiopaque mass with a thin radiolucent margin with the root of the tooth. The mass may be rounded or irregular in shape. Resorption of related tooth's roots is common, but the tooth remains vital (Fig.17) (Sumer M et al., 2006). 


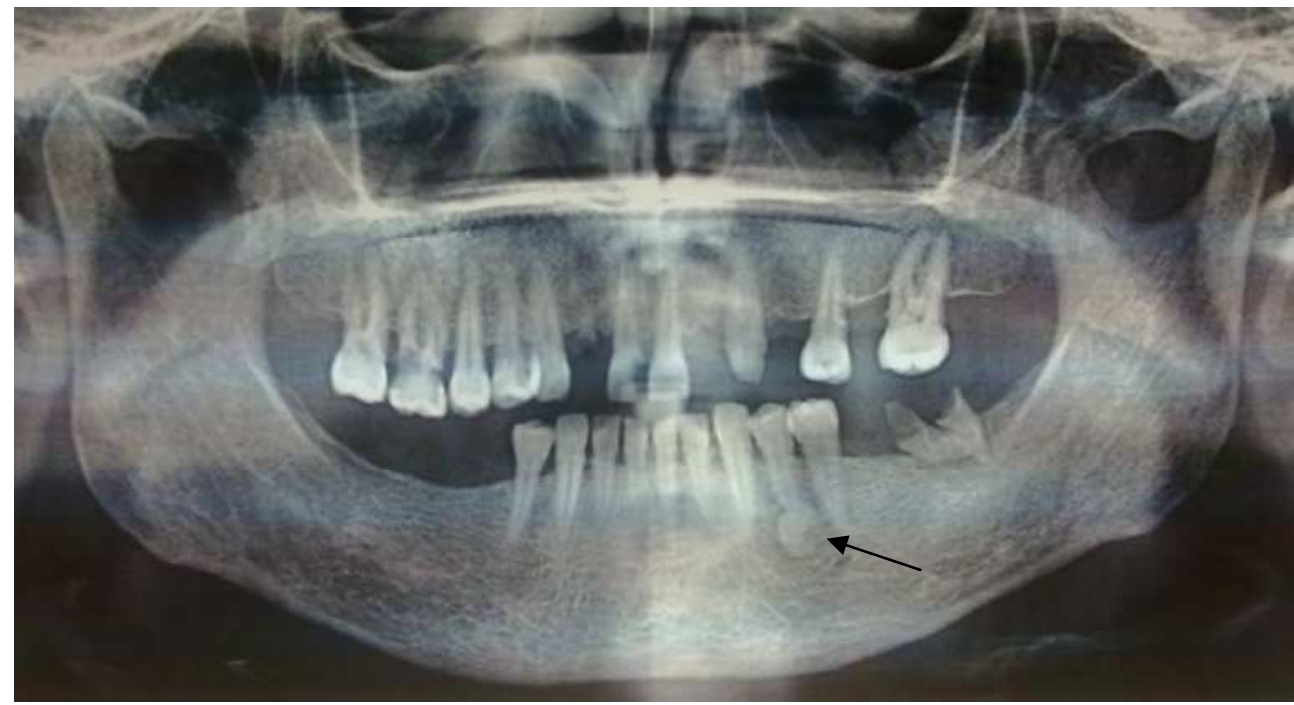

Fig. 17. Panoramic radiographic view of cementoblastoma related to mandibular premolar tooth.

\section{Focal osseous-dysplasia}

The current classification of fibro-osseous lesions, released in 2005 by the World Health Organization (Barnes et al.,2005), is based on age, sex and histopathologic, radiographic and clinical characteristics, as well as location of the lesion. Focal osseous dysplasia is an asymptomatic benign malformation and belonging to the group of fibro-osseous lesions. Although the etiology and pathogenesis of focal osseous-dysplasia are unknown, histogenetically it is believed that it originated from periodontal ligament. It usually appears in dentate and/or edentulous posterior mandibular region. Radiographically, the lesion is well defined by radiolucent borders and an unilocular dense radiopaque appearance. No treatment is necessary for focal osseous dysplasia and follow-up is essential to confirm the diagnosis. Some authors have suggested that the transformation into florid cemento-osseous dysplasia is possible and should be considered at recall visits (Fig.18) (Summerlin \&Tomich, 1994).

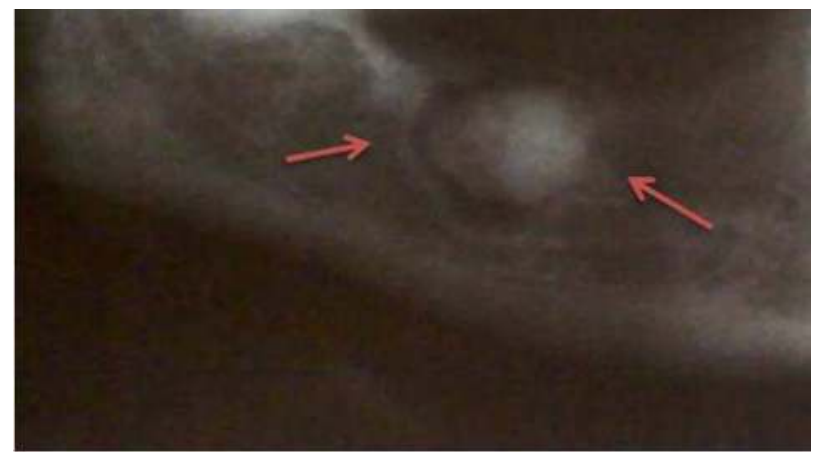

Fig. 18. Periapical radiographic view of focal osseous dysplasia in mandible 


\section{Odontogenic myxoma}

Odontogenic myxoma derives from dental mesenchyme and generally affects the young persons (of average age 15 years). It usually affects in the mandible, and typically appears in the mandibular angles. It has benign behaves but can infiltrate widely. Due to the inadequate surgical excision, it may recur. Radiographically, the odontogenic myxoma may produce several types: unicystic, multilocular, pericoronal and radiolucentradiopaque and it is close resemblance to soap bubble-like picture of ameloblastoma. The lesion gives rise to fusiform swelling and radiolucent area with scalloped margins. The treatment of odontogenic myxoma is required wide excision but some cases have been seen over 30 years after the first intervention (Fig.19) (Cawson \& Odell, 2002; Wood et al., 1997; Altug et al., 2011a).

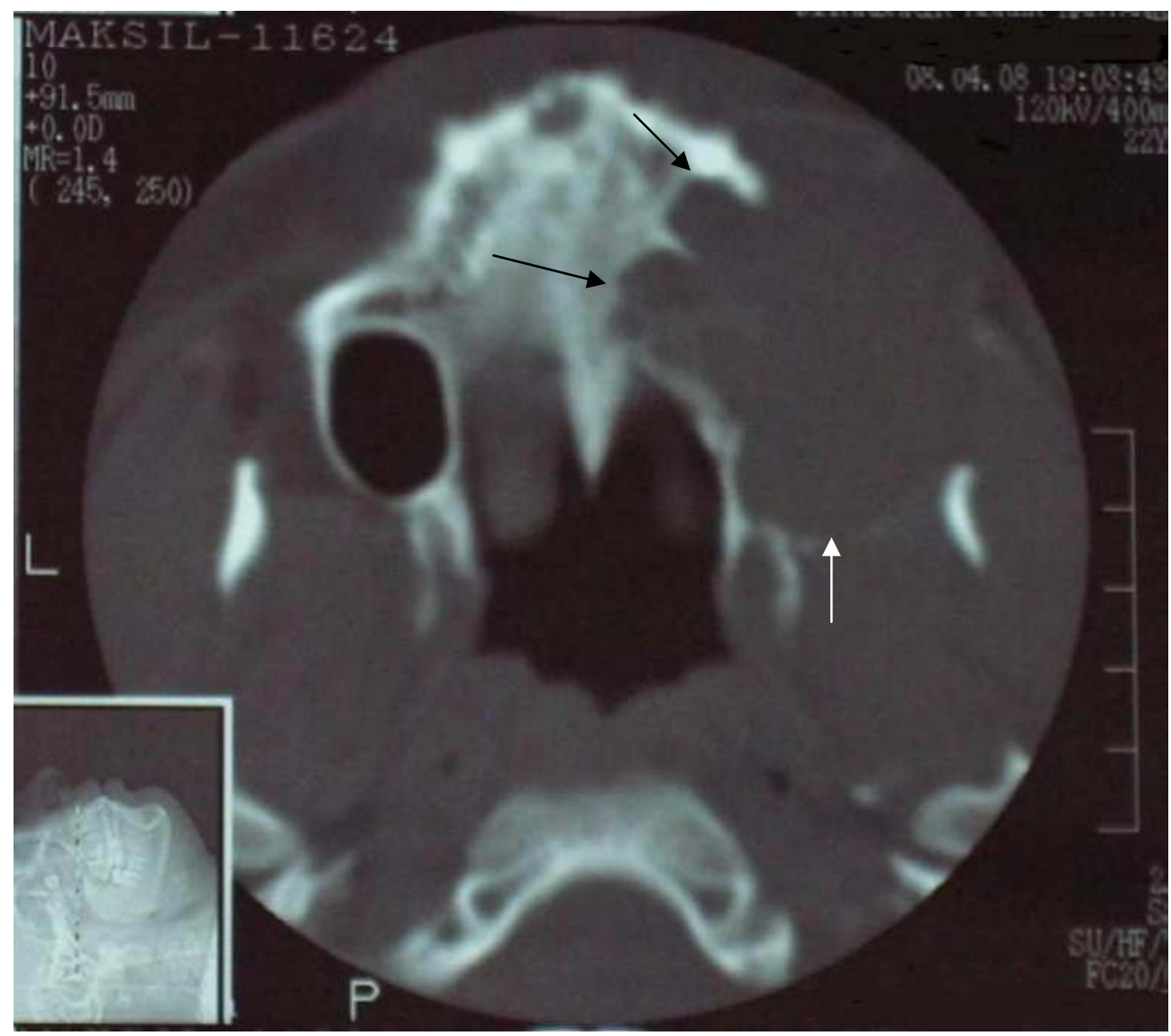

Fig. 19. Axial CT view of maxillary odontogenic myxoma. 


\section{Solitary eosinophilic granuloma}

Solitary eosinophilic granuloma of the jaws belongs to the group of langerhan's cell histiocytosis and causes restricted bone destruction with swelling and pain. It generally occurs in child and young adults. Eosinophilic granuloma can affect almost any bone but, when the jaws are affected mandible is commonly. Radiographically, the lesion has rounded radiolucency and an appearance of teeth floating air. The treatment of eosinophilic granuloma curettage is sufficient and some localize cases spontaneous regression are possible (Fig.20) (Cawson \& Odell , 2002; Altuğ et al.,2010a)

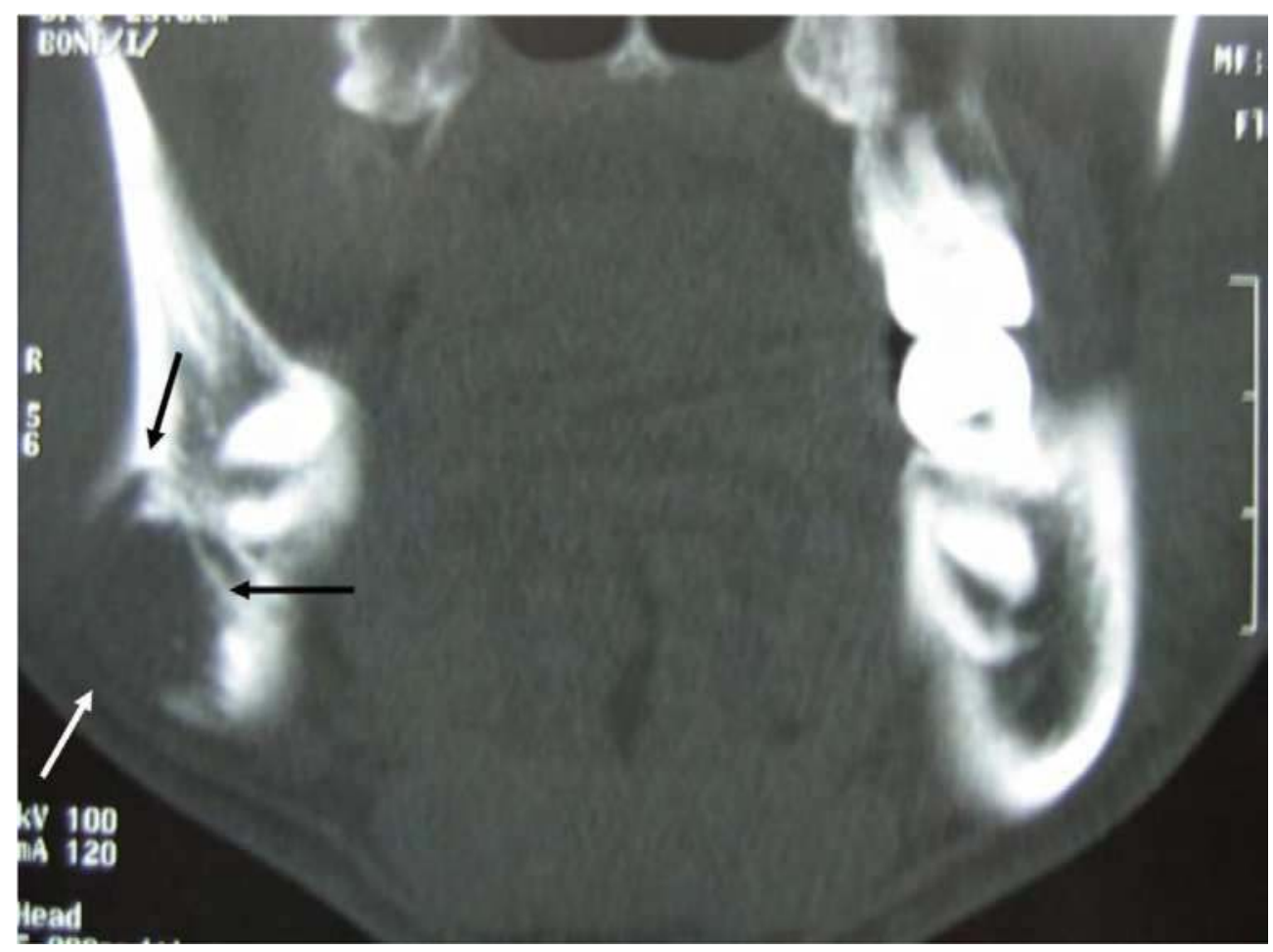

Fig. 20. Coronal CT view of mandibular eosinophilic granuloma.

\section{Conclusion}

Although oral radiology is the precious member of oral diagnosis procedures, only one imaging modality can provide us to wrong diagnosis in maxillofacial region. Especially in cysts/tumors differential diagnosis, it is recommended that combination of different imaging modalities. 


\section{Acknowledgment}

We are grateful to Mrs. Muge Unlukoc, has provided invaluable help throughout including providing us with periapical radiographic illustrations. We would like to thank Mr. Hakan Yamanyar, for English proof-reading.

\section{References}

Altuğ, HA, Alömeroğlu, M, Şahin, S, Şençimen, M, Doğan, N. \& Krıshnan, DG. (2010a). Incidental discovery asymptomatic radiolucent lesion of the posterior mandible. $J$ Oral Maxillofac Surg, Vol.68. pp:845-848 ISSN 0278-2391

Altug, HA, Altug, H, Sari, E, Sencimen, M. \& Altun C. (2010b). Diagnosis and surgically management of supernumerary teeth in both the primary and the permenant dentitions. The Journal of Gazi University Faculty of Dentistry. Vol.27. pp:77-82 ISSN 1300-3100

Altuğ, HA, Gülses, A \& Şençimen M. (2011a). Clinico-radiographic Examination of Odontogenic Myxoma with Displacement of Unerupted Upper Third Molar: Review of the Literature. Int J Morphol 29(3):930-933 ISSN 07179367

Altuğ, HA, Şençimen, M, Altun, C \& Guven G. (2011b). Computed tomography and magnetic resonance imaging of giant cell granuloma of the mandible. Int J Comp Asist Radiol Surg. 6:s384-s385 ISSN 18616410

Barnes, L, Eveson, JW, Reichart, P. \& Sidransky, D. (2005). Classification of Tumors In: Pathology E Genetics Head and Neck Tumours. IARCPress, ISBN 928322417 5, Lyon, France

Cawson, RA. \& Odell, EW. (2002). Hard Tissue Pathology, In: Cawson's Essentials of Oral Pathology and Oral Medicine. Seventh edition, 102-158, ISBN 0443 071055, Spain

Curtin, HD., Ishwaran, H., Mancuso, AA., Dalley, RW., Caudry, DJ. \& McNeil, BJ. (1998). Comparison of CT and MR imaging in staging of neck metastases. Radiology, Vol.207(1):123-130, ISSN 0033-8419

Daley, TD. \& Wysocki, GP. (1995). The small dentigerous cyst. A diagnostic dilemma. Oral Surg Oral Med Oral Pathol Oral Radiol Endod, Vol.79, pp:77-81,101-120 ISSN 10792104

DelBalso, AM. (1998). An approach to the diagnostic imaging of jaw lesions, dental implants, and the temporomandibular joint. Radiol Clin North Am. Vol. 36, pp:85590 ISSN 00338389

Escobar, E, Godoy, L. \& Peñafiel, C. (2007). Odontogenic Cysts: Analysis of 2.944 cases in Chile Germán Ochsenius. Med Oral Pathol Oral Cir Bucal, Vol.12,pp:E85-91, eISSN 1698-6946

Frederiksen, NL. (2004). Specialized Radiographic Techniques, In: Oral Radiology: Principles and Interpratation, White, SC.\&Pharoah, MJ, (Ed), 245-250, Mosby, ISBN 978-0-32302001-5, China

Hermans, R., De Keyzer, F.\& Vandecaveye V. (2006). Imaging Tecqnique, In: Medical Radiology, Diagnostic Imaging, A.L. Baert, K.Sartor, (Ed),31-43, Springer-Verlag, ISBN 3-540-22027-5, Germany

Karjodkar, FR. (2006). History of Radiology, In: Textbook of Dental and Maxillofacial Radiology,1-11, Jaypee Brothers Medical Publishers, ISBN 81-8061-854-4, India 
Lurie, AG. (2004). Panoramic Imaging, In: Oral Radiology: Principles and Interpratation, White, SC.\&Pharoah, MJ, (Ed), 191-195, Mosby, ISBN 978-0-323-02001-5, China

Mendes, RA, Carvalho, JF. \&Van der Waal, I. (2010). Characterization and management of the keratocystic odontogenic tumor in relation to its histopathological and biological features. Oral Oncol. Vol.46, No.4, pp:219-225, ISSN 13688375

Ortakoğlu, K, Aydıntuğ, YS, Altug, HA, Okçu, KM. \& Günhan Ö. (2006). Benign fibroosseous lesions. The Turkish J Dentistry Vol.65. pp:132-136 ISSN 1304-6071 Pasler, FA\& Visser, H. (2003). Radiographic Anatomy in Intraoral Radiographs, In : Pocket Atlas of Dental Radiology, 70-80, Thieme, 978-3-13-139801-7, USA

Pasler, FA. (1993). Radiographic Anatomy of Special Region, In: Color Atlas of Dental Medicine.Radiology, K.H. Rateitschak, H.F. Wolf, (ed),71-80,Thieme, ISBN 3-1378901-6,USA.

Şahin, S, Saygun, NI, Çanakçı, CF, Öngürü, Ö. \& Altug HA. (2009). Root canal treatment failure mediated lateral radicular cyst: Case report. T Klin J Dental Sciences, Vol.15. pp: 214-219 ISSN 1300-7734

Scholl, RJ, Kellett, HM, Neumann, DP. \& Lurie, AG. (1999). Cysts and cystic lesions of the mandible: clinical and radiologic-histopathologic review. Radiographics Vol.19. pp:1107-24 ISSN 02715333

Sumer, M, Gunduz, K, Sumer, AP. \& Gunhan O. (2006). Benign cementoblastom A case report. Med Oral Patol Oral Cir Bucal. Vol. 11. pp:e483-4855. ISSN 1698-6946

Summerlin, DJ. \& Tomich, CE. (1994). Focal cemento-osseous dysplasia: a clinico-pathologic study of 221 cases. Oral Surg Oral Med Oral Patho Oral Radiol Endod, Vol. 78. pp:61120, ISSN 1079-2104

Weber, AL. (1993). Imaging of the cyst and odontogenic tumors of the jaw. Definition and classification. Radiol Clin North Am, Vol.31,pp:101-120, ISSN 00338389

Whaites, E. (2002). Periapical Radiograph, In: Essential of Dental Radiograhy and Radiology, 75100, Harcourt Publihers Limited, ISBN 0443-07027-X, China

White, SC.\& Pharoah, MJ. (2004). Intraoral Radiographic Examinations, In :Oral Radiology: Principles and Interpratation, 121-126, Mosby, ISBN 978-0-323-02001-5, China

Wood, NK., Goaz PW., Jacobs MC. (1997). Periapical Radiolucencies, In: Differential Diagnosis of Oral and Maxillofacial Lesions, N.K. Wood, P.W. Goaz, (Ed), 252279,Mosby, ISBN 0-8151 9432-3, St Louis, USA 


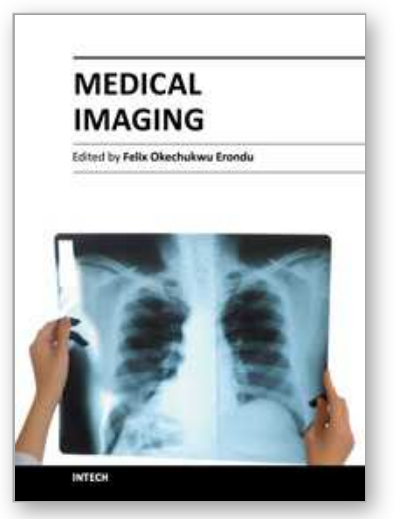

\author{
Medical Imaging \\ Edited by Dr. Okechukwu Felix Erondu
}

ISBN 978-953-307-774-1

Hard cover, 412 pages

Publisher InTech

Published online 22, December, 2011

Published in print edition December, 2011

What we know about and do with medical imaging has changed rapidly during the past decade, beginning with the basics, following with the breakthroughs, and moving on to the abstract. This book demonstrates the wider horizon that has become the mainstay of medical imaging sciences; capturing the concept of medical diagnosis, digital information management and research. It is an invaluable tool for radiologists and imaging specialists, physicists and researchers interested in various aspects of imaging.

\title{
How to reference
}

In order to correctly reference this scholarly work, feel free to copy and paste the following:

Hasan Ayberk Altug and Aydin Ozkan (2011). Diagnostic Imaging in Oral and Maxillofacial Pathology, Medical Imaging, Dr. Okechukwu Felix Erondu (Ed.), ISBN: 978-953-307-774-1, InTech, Available from: http://www.intechopen.com/books/medical-imaging/diagnostic-imaging-in-oral-and-maxillofacial-pathology

\section{INTECH}

open science | open minds

\section{InTech Europe}

University Campus STeP Ri

Slavka Krautzeka 83/A

51000 Rijeka, Croatia

Phone: +385 (51) 770447

Fax: +385 (51) 686166

www.intechopen.com

\section{InTech China}

Unit 405, Office Block, Hotel Equatorial Shanghai

No.65, Yan An Road (West), Shanghai, 200040, China

中国上海市延安西路65号上海国际贵都大饭店办公楼 405 单元

Phone: +86-21-62489820

Fax: +86-21-62489821 
(C) 2011 The Author(s). Licensee IntechOpen. This is an open access article distributed under the terms of the Creative Commons Attribution 3.0 License, which permits unrestricted use, distribution, and reproduction in any medium, provided the original work is properly cited. 